\title{
Nursing-Induced Somatosensory Cortex Plasticity: Temporally Decoupled Changes in Neuronal Receptive Field Properties Are Accompanied by Modifications in Activity- Dependent Protein Expression
}

\author{
Céline Rosselet, Yoh’i Zennou-Azogui, and Christian Xerri \\ Neurobiologie Intégrative et Adaptative, Unité Mixte de Recherche 6149, Université de Provence, Centre National de la Recherche Scientifique, 13331 \\ Marseille Cedex 03, France
}

\begin{abstract}
This study is an attempt to gain insight into the malleability of representational maps in the primary somatosensory cortex in relation to the expression of proteins involved in inhibitory and excitatory neurotransmitter systems that contribute to maintain these maps in a dynamic state. Malleability of somatosensory maps is characterized by changes in the sizes of neuron receptive fields (RFs) affecting the representational grain and in the locations and submodalities of these RFs modifying the map extent. The concomitance of these alterations remains so far hypothetical. We used nursing as an evolving source of ethologically significant cutaneous stimulation. This cyclic behavior is particularly suited to investigating the time course of experience-dependent cortical changes. Electrophysiological maps of the ventrum skin were recorded twice in the same lactating rats between nursing initiation and several weeks after nursing. We found that reduction in RF size occurred earlier than map expansion. As nursing time declined, the map expansion was maintained longer than the RF sharpening. Based on this difference in time course, we compared the expression patterns of several activity-dependent proteins in relation to the RF plasticity. Western blot analysis showed an increase in glutamic acid decarboxylase expression that was concomitant with RF contraction. In contrast, NR2A subunit of NMDA and $\alpha$ calcium/calmodulin kinase type II were upregulated at times when map expansion was observed. We propose that inhibitory and excitatory plasticity mechanisms operating with different time courses may contribute to the temporal dissociation of nursing-induced RF reshaping and map expansion.
\end{abstract}

Key words: cortical plasticity; GAD; NMDAR-NR2A subunit; $\alpha$-CaMKII; electrophysiological mapping; lactation

\section{Introduction}

Somatotopic maps in the primary somatosensory (SI) cortex are continuously modified by recent experience and learning. Usedependent changes in size, location, and sensory submodality of cortical neuron receptive fields (RFs) alter the organizational features of the somatotopic maps. Numerous studies have documented the time course of map changes after nerve section or digit amputation (Turnbull and Rasmusson, 1991; Calford, 2002; He et al., 2004). In contrast, very little is known about the time course and reversibility of experience-dependent map remodeling. Cutaneous stimuli induced by nursing gradually abate in a naturalistic context. This episodic behavior has been shown to reshape the SI representation of the ventrum skin of lactating rats (Xerri et al., 1994). It is unknown how the rapidly evolving nursing behavior impacts on the ventrum map in the course and after

\footnotetext{
Received April 7, 2006; revised Aug. 29, 2006; accepted Aug. 29, 2006.

This work was supported by grants from Ministère de l'Enseignement Supérieur et de la Recherche and Centre National de la Recherche Scientifique. We thank Abdessadek Elahmadi for his assistance in statistical analysis.

Correspondence should be addressed to Dr. Christian Xerri, Neurobiologie Intégrative et Adaptative, Unité Mixte de Recherche 6149, Université de Provence, Centre National de la Recherche Scientifique, Pole 3C, Case B, 3 Place Victor Hugo, 13331 Marseille Cedex 03, France. E-mail: xerri@up.univ-mrs.fr.

DOI:10.1523/JNEUROSCI.3253-06.2006

Copyright $\odot 2006$ Society for Neuroscience $\quad 0270-6474 / 06 / 2610667-10 \$ 15.00 / 0$
}

completion of nursing. In addition, it is uncertain whether changes in RF size altering the representational grain of the maps develop in parallel with changes in RF location and/or submodality leading to map expansion or contraction. The first objective of the present study was to investigate the time course and reversibility of nursing-induced electrophysiological changes in these SI neuronal RF properties.

Cortical maps are dynamically reshaped through ongoing adjustments in the balance of excitatory and inhibitory influences on their constituent neurons. The common view is that drastic, i.e., deafferentation-induced, or more subtle, i.e. experiencedependent, disruption in this balance alters the RF properties of SI neurons through weakening/strengthening of thalamocortical and intracortical synapses. GABAergic inhibition that sharpens cortical neuron RFs in SI (Dykes et al., 1984; Tremere et al., $2001 \mathrm{a}$,b; Foeller et al., 2005) is regulated in a use-dependent manner through alteration of glutamic acid decarboxylase (GAD) expression (Welker et al., 1989a,b; Gierdalski et al., 2001) and formation of GABA synapses (Knott et al., 2002). The NMDA subtype of glutamate receptors (NMDARs) is crucially involved in strengthening excitatory synapses (Malenka and Nicoll, 1999; Kind and Neumann, 2001) and contributes to the experiencedependent malleability of SI representations (Jablonska et al., 
1996, 1999; Rema et al., 1998). In particular, the NR2A subunit of NMDAR, which plays an important role in long-term potentiation (LTP) (Liu et al., 2004; Massey et al., 2004), is regulated by sensory experience (Quinlan et al., 1999; Barria and Malinow, 2002) and increased in SI as a result of tactile training (Skibinska et al., 2005). Furthermore, NMDAR opening mediates a transient increase in postsynaptic $\mathrm{Ca}^{2+}$ concentration, leading to activation and translocation of $\alpha$ calcium/calmodulin kinase type II ( $\alpha$-CaMKII) to the postsynaptic density. Necessary for LTP induction (Lledo et al., 1995; Lisman et al., 2002), this enzyme is involved in neocortical experience-dependent plasticity (Glazewski et al., 1996, 2000; Taha et al., 2002, Hardingham et al., 2003). The second aim of our study was to search for the sequence of changes in GAD, NR2A, and $\alpha$-CaMKII protein levels in the time course of nursing-induced cortical map reorganization and to attempt to determine whether these changes may contribute differently to modifying the grain and areal extent of ventrum skin representation in SI.

\section{Materials and Methods}

All experiments have been performed in accordance with the National Institute of Health Guide for Care and Use of Laboratory Animals (publication number 80-23) revised 1996 for the United Kingdom Animals (Scientific Procedures) act 1986 and associated guidelines, or the Policy on Ethics approved by the Society for Neuroscience in November 1989 and amended in November 1993. All efforts were made to minimize the number of animals used and their suffering.

\section{Animals}

Seventy-four adult female Long-Evans rats $(240 \pm 20 \mathrm{~g})$ were used in the present study. All nursing rats were primiparous and were allowed to nurse from parturition to days 21-23 postpartum. A total number of 45 maps were elaborated from 30 rats, using high-density electrophysiological recordings. Single maps were derived from 16 rats (nine virgins; $6-7$ $\mathrm{d}$ postpartum, three nursing rats; $12-15 \mathrm{~d}$ postpartum, four nursing rats). Based on changes in daily nursing time, we performed doublemapping procedures in 14 rats: $6-7$ and $21-23$ d postpartum $(n=5)$; $12-15 \mathrm{~d}$ postpartum and $29-30 \mathrm{~d}$ after end of nursing $(n=4) ; 21-23 \mathrm{~d}$ postpartum and $15-16 \mathrm{~d}$ after nursing $(n=5)$ (Fig. 1). Exceptionally, three maps could be obtained from one nursing rat ( 7 and $28 \mathrm{~d}$ postpartum and $30 \mathrm{~d}$ after weaning). Single-unit recordings were performed twice in two rats, at two times postpartum (11 and $21 \mathrm{~d} ; 12$ and $22 \mathrm{~d}$ ). Immunoblotting analysis was performed on 12 nursing and 12 nonnursing primiparous rats (six nursing and six non-nursing, at $6-7 \mathrm{~d}$ postpartum; six nursing and six non-nursing, at 21-23 d postpartum) and complementary groups of six rats each (virgins, $12 \mathrm{~d}$ postpartum and $15 \mathrm{~d}$ after end of nursing).

The number of pups per nursing mother was maintained at 10. Surplus pups from these rats and all pups from non-nursing rats were removed on the day of birth and given to other lactating rats, not used in the present study, until weaning. For lactating mothers, nursing behavior was unperturbed until the initiation of the mapping session. For animals subjected to double mapping, pups remained in their cage during the recording session. Lactation was reinitiated as soon as the mother returned to the cage. This interruption in lactation, which lasted $\sim 10 \mathrm{~h}$, did not seem to alter the pups' behavior and weight gain.

\section{Nursing time evaluation}

Estimation of daily nursing time was based on videotape recording analysis. Four nursing rats and their pups were videotaped for two $4 \mathrm{~h}$ sessions per day, at days 6,12 , and 18 postpartum. Off-line analysis deter-
Double maps

$(n=4)$

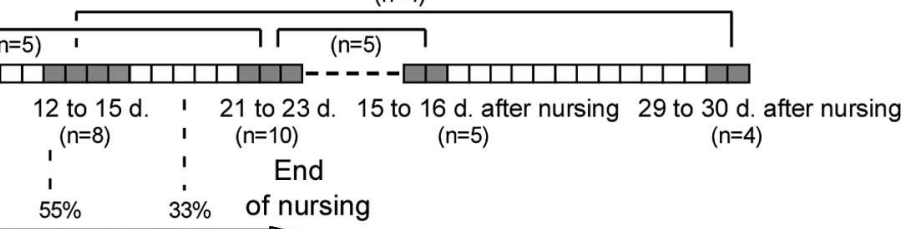

spent in nursing

Figure 1. Synoptic representation of mapping sessions. Time points of mapping from the onset of nursing to a $30 \mathrm{~d}$ postnursing period are shown as shaded rectangles. Numbers between parentheses refer to the sample sizes used in each experimental group. Virgin rats were used as controls $(n=9)$. Double maps obtained from individual nursing rats are indicated by horizontal connecting lines. Two additional rats used for single-unit RF recording are not included. Estimation of the time spent in daily nursing based

mined the time spent in nursing, expressed in percentages of total time recorded daily for each rat. Mean $\pm \mathrm{SD}$ values were calculated for each postpartum time point.

\section{Electrophysiological mapping}

Surgical preparation. Anesthesia was induced with isoflurane short inhalation, followed by an intramuscular injection of ketamine $(25 \mathrm{mg} / \mathrm{kg}$, Ketalar; Virbac, Wissous, France) and medetomidine $(0.25 \mathrm{mg} / \mathrm{kg}$, Domitor; Orion Pharma, Espoo, Finland). Rats were maintained at an areflexic level of anesthesia throughout the experiment by supplemental ketamine-medetomidine combination half doses. The core temperature was continuously monitored by a rectal thermistor probe and maintained between 37 and $38^{\circ} \mathrm{C}$ with a feedback-controlled heating pad. The head was placed in a stereotaxic frame. Surgical and recording procedures were performed under sterile conditions. SI cortex was exposed through a craniotomy $\left(\sim 16 \mathrm{~mm}^{2}\right)$ with bregma as a point of reference (anterior, $0.5 \mathrm{~mm}$; posterior, $3.5 \mathrm{~mm}$; lateral, $2-6 \mathrm{~mm}$ ). To prevent cerebral edema, the posterior neck muscles were resected, and the CSF was drained through an opening in the dura covering the foramen magnum. The dura protecting the exposed part of the cortex was incised and resected. The cortical surface was bathed in a thin layer of warm silicone fluid to prevent drying and edema formation. The bone flap was kept in physiological saline at $4^{\circ} \mathrm{C}$. For multiple mapping procedures, the silicone was removed with a wash of warm saline at the end of the recording session, and then the exposed cortical area was covered with a piece of sterile Teflon film. The bone flap was reinserted and stabilized with dental acrylic. Connective tissue was closed with absorbable sutures and the scalp with silk sutures. The animal's temperature was monitored until a complete recovery from anesthesia. An antibiotic $(150 \mathrm{mg} / \mathrm{kg}$, i.m., Pyocefal; Takeda, Osaka, Japan) was administered daily for $7 \mathrm{~d}$. At the end of the final mapping session, rats received a lethal dose of sodium pentobarbital ( $150 \mathrm{mg} / \mathrm{kg}$, i.p.).

Mapping procedure. Long hairs on the trunk were trimmed to facilitate the subsequent determination of cutaneous RF boundaries. We used a high-resolution camera mounted on an operating microscope to obtain images of cortical area to be mapped and the skin surfaces of the contralateral trunk. Locations of microelectrode penetrations and corresponding cutaneous RFs were recorded on the digitized images of the cortex and ventrum, respectively, using Map 0.925 software (Peterson and Merzenich, 1995). A parylene-coated tungsten microelectrode $(\sim 1$ $\mathrm{M} \Omega$ at $1 \mathrm{kHz}$; World Precision Instruments, Hertfordshire, UK) was moved perpendicular to the cortical surface in Cartesian coordinates by a three-dimensional stepping micromanipulator (Märzhauser; Fine Science Tools, Vancouver, British Columbia, Canada). Using the recording artifact generated by the microelectrode contact with the cortex surface as a zero level, we advanced the electrode to a depth of $\sim 650-700 \mu \mathrm{m}$ to record responses from small clusters of neurons (two to four) in layer IV (Waters et al., 1995; Coq and Xerri, 1998). Sites of electrode penetration were identified relative to the vasculature of the cortical surface. Many recording sites were spaced as closely as possible $(\sim 80 \mu \mathrm{m})$, whereas larger distances between electrode penetrations (up to $120 \mu \mathrm{m}$ ) were necessary to avoid surface vessels. Under our recording conditions, the amplitude of the background noise usually ranged from 15 to $20 \mu \mathrm{V}$, 
with a signal-to-noise ratio ranging from 4 to 6 . The multiunit signal was amplified, filtered (bandwidth, $0.5-5 \mathrm{kHz}$ ), and displayed on an oscilloscope. This signal was also rectified and passed through a discriminator whose output signal was proportional to the part of the input signal, which was higher than an adjustable threshold set just above the background noise. The output of the discriminator was then delivered to an audio monitor.

A cutaneous RF of multiunit cluster was defined at each recording site as the discrete area of skin where noticeable skin indentation or gentle rubbing of the fur produced with a sharp paint brush or glass probe elicited reliable increase in multiunit discharge. Grid patterns marked on the rat's fur with insoluble ink served as guides for accurately drawing RFs on the body surface. The reproducibility of RF delineation was systematically checked by two experimenters during the course of the recording sessions. In our classification, noncutaneous responses (NCRs) were identified by responses to taps and pressure, but not cutaneous, stimulation. Cortical sites not exhibiting stimulus-evoked responses but only spontaneous discharges were considered as unresponsive.

In four recording sessions, single and multiple units were recorded with a tungsten microelectrode (impedance, $4 \mathrm{M} \Omega$ at $1 \mathrm{kHz}$ ) moved perpendicular to the cortical surface. Single units were recorded at depths ranging from 650 to $850 \mu \mathrm{m}$. Because some units were spontaneously silent, action potentials of single units were searched while the cortex was activated with cutaneous stimuli. Single units were preselected using a window discriminator (World Precision Instruments) that triggered a standard transistor-to-transistor logic pulse from each action potential. The single-unit RF was determined by listening to the pulse trains through the audio speaker, while using the same stimulation procedure as that of the multiunit RFs (Chapin and Lin, 1984). Both the raw recording signal and the standard pulses were sent to a computer for storage and subsequent analysis. In every recording session, 8-10 units were sampled in each of six microelectrode penetrations spanning the ventrum representational area in the rostrocaudal direction. After single-unit recordings were completed in a penetration, the electrode was moved to a depth of $\sim 750 \mu \mathrm{m}$. Then, the trigger threshold was lowered so that a cluster of units was discriminated above the noise level to define the corresponding multiunit RF. Off-line spike sorting was performed with Spike2 software (Cambridge Electronic Design, Cambridge, UK). Spike sorting yielded samples of 5-6 of the 10 units preselected in every microelectrode penetration. In each of the two rats used for single-unit RF recording, the locations of the six penetrations explored in the first recording session were used to perform the second recording session in similar cortical locations, as determined by reference to unchanged vascular landmarks.

The sizes of multiunit and single-unit RFs were measured off-line, after proper calibration, using Map 0.925 software. After completion of all recording sessions, we used Canvas software (Deneba, Miami, FL) to elaborate maps of the ventrum skin representation by drawing boundaries encompassing cortical sites whose multiunit RFs were centered to a common skin subdivision (e.g., anterior, middle, or posterior third). Borders were drawn midway between adjacent recording sites in which RFs were located on distinct skin subdivisions. When RFs overlapped the boundaries of different skin subdivisions, the cortical representational boundary was drawn to reflect the proportional skin surface representations reflected by these boundary RFs. Map borders were placed midway between sites responsive and unresponsive to cutaneous stimulation. The areal extent of each region of the cutaneous map was then calculated using Canvas software.

Measurements. The sizes of the cortical areas serving the ventrum skin were expressed in square millimeters. Average values were computed for each group of rats. The absolute sizes of RFs, measured in square millimeters, were normalized relative to the total ventrum skin surface because the surface area of the ventrum was greater in lactating than in nonlactating rats. The mean size of the multiunit RFs was calculated for each rat, and a mean value was computed for each group of rats. An average RF size was calculated for each sample of single units recorded at the same cortical site. All mean values computed at 11 and $12 \mathrm{~d}$ postpartum were included in the same population, as were the mean values obtained at 21 and $22 \mathrm{~d}$ postpartum, for subsequent comparison between the two distant periods.

\section{Quantitative Western blotting}

Tissue preparation. Tissue samples $(\sim 10 \mathrm{mg})$ were dissected from an area of SI cortex centered on the ventrum representation, frozen on dry ice, and stored at $-80^{\circ} \mathrm{C}$. These samples were defrosted and homogenized in a $20 \mathrm{~mm}$ Tris-Cl buffer, $\mathrm{pH}$ 7.5, containing $1 \mathrm{~mm}$ EDTA, a protease inhibitor cocktail (Complete, Mini, EDTA-free, 1 tablet of $10 \mathrm{ml}$ buffer; Roche Diagnostics, Meylan, France), $1 \%$ SDS, $10 \%$ Triton X-100, and $2 \mathrm{M}$ DTT. After homogenate centrifugation $(10,000 \times g, 10 \mathrm{~min})$, protein concentration of resulting supernatant was estimated using the Bradford method (Bradford, 1976) with BSA as standard. Sample proteins were denatured in a $250 \mathrm{~mm}$ Tris-Cl loading buffer, $\mathrm{pH}$ 6.8, containing EDTA $100 \mathrm{~mm}, 2 \%$ SDS, $10 \%$ glycerol, $1 \% \beta$-mercaptoethanol, and bromophenol blue, heated at $95^{\circ} \mathrm{C}$ for $10 \mathrm{~min}$.

Western blot analysis. Each aliquot was loaded in duplicate onto a SDS-polyacrylamide gel (GAD, $\alpha$-CaMKII, and NR2A at 20, 10 , and 40 $\mu \mathrm{g}$ of proteins, respectively). Proteins were separated by electrophoresis using $8 \%$ acrylamide gel for $\alpha$-CaMKII $(50 \mathrm{kDa})$ and GAD $(65-67 \mathrm{kDa})$ and $6 \%$ acrylamide gel for NMDA $\varepsilon 1$ (NR2A) subunit $(177 \mathrm{kDa})$ and were then transferred onto nitrocellulose membranes $(0.45 \mu \mathrm{m}$; Schleicher \& Schuell, Dassel, Germany). The membranes were blocked with $3 \% \mathrm{BSA}$ in a Tris buffer saline, $\mathrm{pH} 8$, for $1 \mathrm{~h}$ at room temperature and then incubated overnight at $4^{\circ} \mathrm{C}$ in a primary antibody: anti- $\alpha$-CaMKII (monoclonal antibody, 1:2000; Boehringer Mannheim, Mannheim, Germany), anti-GAD 65/67 (polyclonal antibody, 1:1000; Santa Cruz Biotechnology, Santa Cruz, CA), and anti-NMDA $\varepsilon 1$ (polyclonal antibody, 1:1000; Santa Cruz Biotechnology). A monoclonal antibody (Chemicon, Temecula, CA) against actin, an ubiquitous cytoskeletal protein, was used as an equal loading control (1:5000 for NR2A and 1:2500 for $\alpha$-CaMKII and GAD controls). Incubation in secondary antibody conjugated to horseradish peroxidase (1:20,000; Jackson ImmunoResearch, West Grove, PA) was performed for $1 \mathrm{~h}$ at room temperature. Chemiluminescence was captured on autoradiography film using an ECL kit (Super Signal West Pico; Pierce, Rockford, IL). Western blot analysis for each sample was duplicated, and the mean values were included in statistical analysis.

Measurements by densitometry. Western blot bands were digitized with a computer-assisted scanner (Epson perfection 2400) and analyzed with a software (NIH Image 1.6), which determines automatically the labeled region and subtracts the background values above and below the protein band. For each protein band, the mean optical density per pixel was measured, based on a third-degree polynomial curve calibration. An integrated density (ID) value, which corresponded to the sum of pixel values, was calculated. This ID value was normalized to the ID of an immunoblot for actin.

\section{Statistical analysis}

SAS Proc Mixed repeated measurement procedure (SAS/Stat. 9.0 software; SAS Institute, Cary, NC) was used to evaluate cortical map area and multiunit RF size changes over postpartum time. Mixed models were required because double maps were not derived from each rat, thus resulting in missing data. ANOVA was followed by Bonferroni's correction for multiple comparisons. All statistical comparisons were performed using this statistical procedure, unless otherwise indicated. The Wilcoxon's matched-pairs signed-ranks test was used for comparing single-unit RFs, and Mann-Whitney $U$ test was used for comparing multiunit RFs recorded within the two postnursing periods examined (Statistica 5.0 software; StatSoft, Tulsa, OK). Statistical treatment of immunoblots was done with ANOVA supplemented with multiple comparisons (Newman-Keuls post hoc test) using Statistica 5.0.

\section{Results \\ Electrophysiological maps}

The cutaneous representations of the ventral trunk skin elaborated in the present study are based on high-density electrophysiological mapping (total number of recordings, 4576). We attempted to determine whether the decrease in RF sizes, refining the representation grain of cortical maps, and changes in the RF locations and submodalities, modifying the topography and in- 


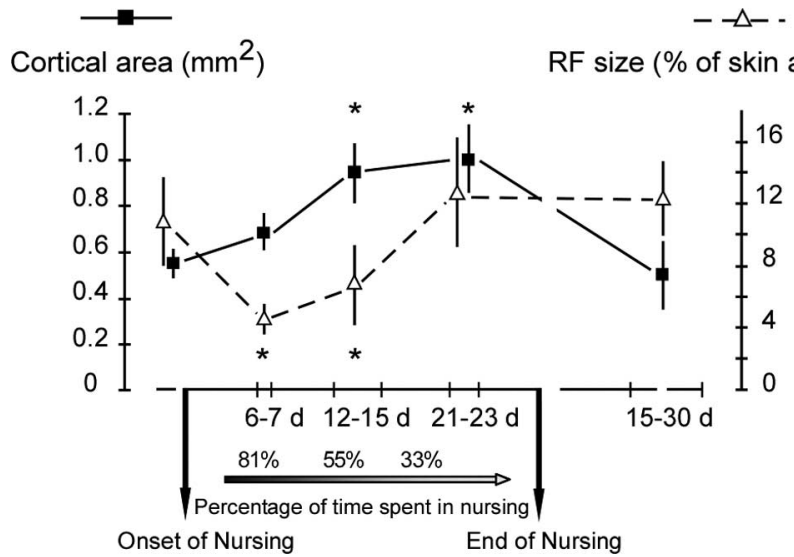

Figure 2. Time course of changes in cortical map areal extent and RF size over the nursing and postnursing periods. The cortical area serving the ventrum skin (filled squares; means \pm SD) showed a significant enlargement only beyond the first week postpartum. This expansion was maintained within the 12-23 d postpartum period examined, whereas daily nursing time gradually decreased to $\sim 30 \%$ at the end of the third week postpartum. The map areas recorded within the $15-16$ or $29-30$ d periods after the nursing period were similar to those obtained before nursing. RF sizes (open triangles; means \pm SD) decreased as early as the end of the first week postpartum and progressively returned to control values by the end of the third week postpartum. * Significant differences versus all other groups (see Results for $p$ values).

creasing the areal extent of the maps (Xerri et al., 1994), occur concomitantly. Furthermore, we investigated how these RF properties evolve from the end of the first week to that of the third week postpartum, as nursing time gradually declines, and 2-4 weeks after nursing completion.

\section{RF sizes decrease before cortical map expands during the early nursing period}

According to Grota and Ader $(1969,1974)$, female rats spend $\sim 80 \%$ of their time nursing during the first days postpartum. Nursing time gradually declines to $\sim 25 \%$ by day 17 postpartum. These values are consistent with our own videotape data that indicated an average of $81 \pm 5 \%$ on the day 6 postpartum, $\sim 55 \pm$ $7 \%$ by the end of the second week post-partum, and $33 \pm 8 \%$ by the day 18 postpartum. We first addressed the question as to whether gradual changes in daily nursing time affect the SI neuron RF properties. The mean sizes of multiunit RFs and areas of ventrum representations were compared in five groups of rats: virgins, 6-7, 12-15, and 21-23 d of nursing, and 15-30 d after the end of nursing. ANOVA yielded significant effects of postpartum time on the cortical map extent $\left(F_{(4,10)}=30.50 ; p<0.0001\right)$ and RF sizes $\left(F_{(4,10)}=16.19 ; p<0.0002\right)$. Did the decrease in cutaneous RF size reported previously take place as early as the end of the first week postpartum? Indeed, the multiunit RF sizes ( $4.55 \pm$ $0.71 \%$ of ventrum skin area; mean \pm SD) recorded within the $6-7 \mathrm{~d}$ postpartum period were significantly smaller $(p<0.007)$ than those obtained in control virgin rats $(10.52 \pm 2.98 \%)$. This decrease is similar to that reported in our previous study (Xerri et al., 1994). Surprisingly, the ventrum skin representation was not yet enlarged at the end of the first week postpartum, as indicated by similar values of map areal extent recorded in nursing $(0.68 \pm$ $\left.0.08 \mathrm{~mm}^{2}\right)$ and virgin $\left(0.55 \pm 0.05 \mathrm{~mm}^{2}\right)$ rats $(p=0.99)$ (Fig. 2). Over the next $12-15 \mathrm{~d}$ postpartum period examined, the decrease in multiunit RF sizes was maintained $(6.93 \pm 2.54 \%$; $p<0.01)$. The area of ventrum skin representation was significantly expanded $\left(0.94 \pm 0.13 \mathrm{~mm}^{2}\right)$ compared with the area recorded before nursing $(p<0.0003)$ and from days $6-7$ postpartum $(p<0.004)$, indicating that this expansion occurred between 7 and $12 \mathrm{~d}$ postpartum (Fig. 2). The recorded expansion ratio $(1.4 \times)$ is close to that observed in previous study $(1.6 \times)$.

\section{RF sizes return to control values before cortical map area as nursing time declines}

The temporal decoupling in the onset of multiunit RF size decrease and map expansion raised the intriguing question of how these organizational features evolve as nursing time abates. As shown in Figures 2 and 3, the data recorded at the end of the nursing period, between days 21 and 23 of lactation, indicates that the sizes of ventrum multiunit RFs $(12.38 \pm 3.52 \%)$ were significantly enlarged compared with those obtained over the $6-7 \mathrm{~d}(4.55 \pm 0.71 \% ; p<0.0007)$ and the $12-15 \mathrm{~d}(6.93 \pm 2.54 \%$; $p<0.005)$ periods of nursing and did not differ from the RF areas measured in control rats $(10.52 \pm 2.98 \% ; p=0.98)$.

The mean values of single-unit RF sizes recorded after $21-22 \mathrm{~d}$ were greater $(5.27 \pm 0.95 \%)$ than those obtained after $11-12 \mathrm{~d}$ ( $1.66 \pm 0.38 \%$; ratio, 3.2) (Wilcoxon's test, $z=3.06 ; p<0.002$ ). The single-unit RF sizes recorded in the 11-12 and 21-22 d periods of nursing represented on average $27.98 \pm 4.21$ and $46.33 \pm$ $9.94 \%$ of the sizes of their corresponding multiunit RFs, respectively (Wilcoxon's test, $z=3.06 ; p<0.002$ ) (Fig. 4). The mean values recorded for the corresponding multiunit RFs (11.35 \pm 1.98 and $4.96 \pm 1.70 \%$, respectively) also showed a significant increase in size between the two periods examined (Wilcoxon's test, $z=3.06$; $p<0.002$ ), although on a smaller proportion (ratio, 2.3), as nursing time declined (Fig. 4). Therefore, both single-unit and multiunit RFs showed a substantial RF increase between the 11-12 and 21-22 d periods of nursing.

The multiunit RF sizes obtained within the two postnursing periods examined had similar mean values $(15-16 \mathrm{~d}, 10.70 \pm$ $0.64 \% ; 29-30 \mathrm{~d}, 13.24 \pm 1.88 \%$; $U=6 ; p=0.17$, Mann-Whitney $U$ test $)$ and were therefore averaged $(11.83 \pm 2.41 \%)$. This mean value was not different from that recorded after the 3 week period of nursing ( $12.38 \pm 3.52 \%$; $p=0.99)$.

Over the 21-23 d nursing period, the cortical area devoted to the ventrum skin was similar $\left(1.00 \pm 0.17 \mathrm{~mm}^{2}\right)$ to that recorded within the $12-15 \mathrm{~d}$ period $\left(0.94 \pm 0.13 \mathrm{~mm}^{2} ; p=1.0\right)$, significantly greater than that found in control rats $\left(0.55 \pm 0.05 \mathrm{~mm}^{2}\right.$; $p<0.0002)$ and after $6-7 \mathrm{~d}$ postpartum $\left(0.68 \pm 0.08 \mathrm{~mm}^{2} ; p<\right.$ 0.004 ) (Fig. 2). Therefore, from the end of the third week postpartum, when nursing time decreased to $\sim 30 \%$, the neuron RF sizes returned to prenursing values, whereas the representation of the ventrum skin remained expanded. Double maps derived from individual nursing rats indicate that this expansion occurred in either the anteromedial or medial directions (four of five rats), mainly at the expense of NCR cortical zones (Fig. 3) or in all neighboring sectors (NCR, flank, forelimb, and hindlimb representations). Similarly, expansion of the cutaneous representations of digit skin surfaces into NCR cortical regions has been reported in monkeys subjected to intensive cutaneous stimulation (Jenkins et al., 1990) or trained in a tactile discrimination task (Recanzone et al., 1992).

Reversibility of the ventrum map expansion induced by nursing was searched over two time periods: $15-16$ and 29-30 d after the end of nursing. The cortical areas recorded within these periods did not differ $\left(0.53 \pm 0.17\right.$ and $0.52 \pm 0.14 \mathrm{~mm}^{2}$, respectively) and were therefore averaged. This mean area was significantly smaller $\left(0.52 \pm 0.15 \mathrm{~mm}^{2}\right)$ than those obtained within the $12-15 \mathrm{~d}\left(0.94 \pm 0.13 \mathrm{~mm}^{2} ; p<0.0001\right)$ and $21-23 \mathrm{~d}(1.00 \pm 0.17$ $\left.\mathrm{mm}^{2} ; p<0.0001\right)$ nursing periods but was similar to the areas measured in control rats $\left(0.55 \pm 0.05 \mathrm{~mm}^{2} ; p=0.98\right)$ (Fig. 2). Therefore, the area of cortical territory serving the ventrum map 


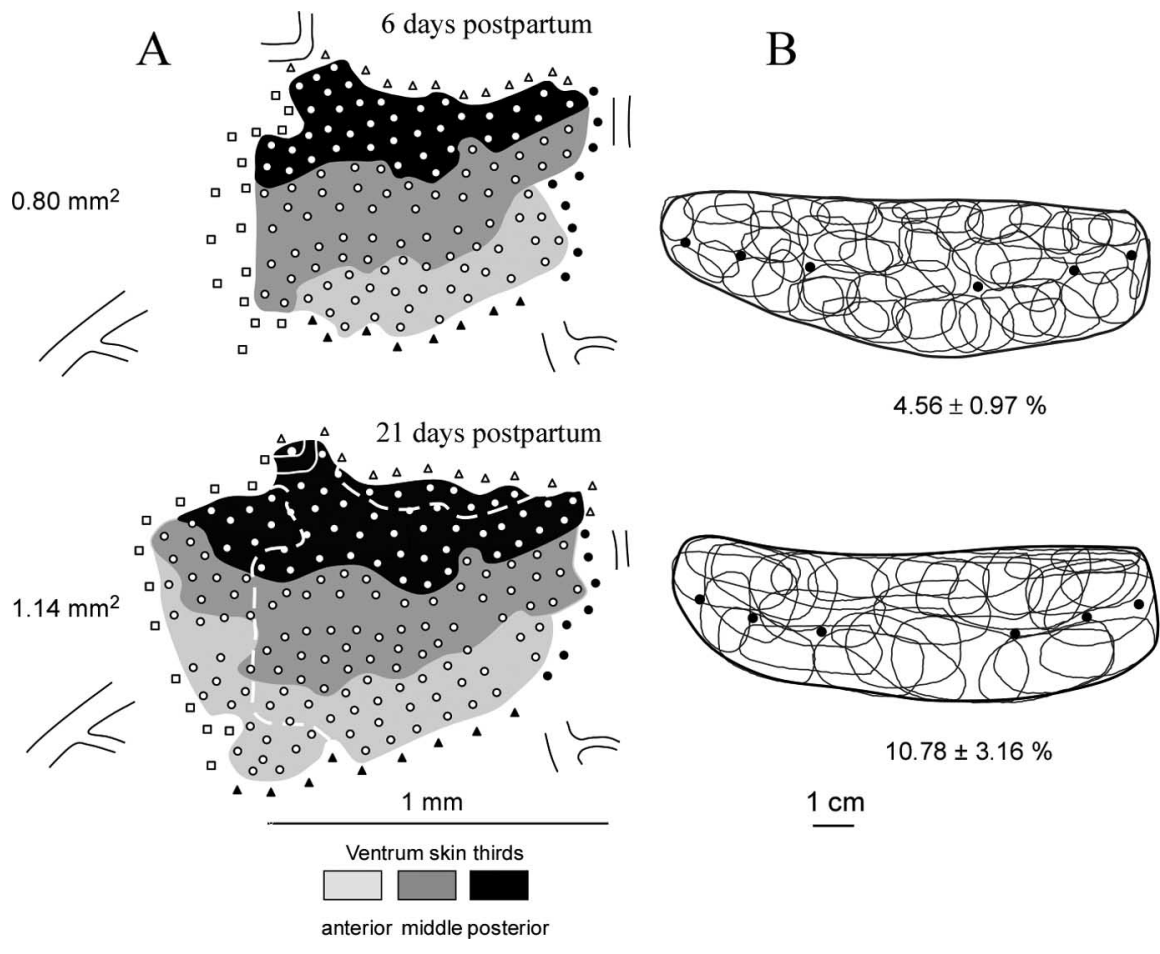

Figure 3. Cortical map expansion and RF sharpening induced by nursing. $\boldsymbol{A}$, Two somatotopic maps were derived from the same rat at days 6 and 21 after nursing initiation. These ventrum skin representations are composed of territories in which RFs were centered on the anterior, middle, and posterior thirds of the ventrum skin. Open circles indicate recording sites in which cutaneous responses were recorded. Open squares mark cortical sites displaying noncutaneous responses elicited by strong pressure on skin. Filled and open triangles refer to sites excited by forelimb and hindlimb stimulation, respectively. The broken lines on the second map outline the main cortical zones over which representational expansion occurred. Constant vascular landmarks are shown in each map to facilitate comparison. $\boldsymbol{B}$, RFs defined on the ventrum skin at the recording sites shown in the corresponding maps. The heavy dark lines outline the ventrum skin. Filled circles indicate the location of nipples. For sake of clarity, $\sim 30 \%$ of the recorded RFs are not shown. Mean \pm SD values of map areal extent and normalized (with reference to total ventrum skin area) RF sizes are indicated for each mapping session. Note that, at day 21 postpartum, when daily nursing time was reduced to $\sim 30 \%$, the ventrum map was still in expansion, whereas the sizes of neuron RFs within the corresponding cortical area were as large as those recorded before nursing.

returned to prenursing values within 2 weeks after nursing. Closer inspection of the paired maps recorded in the same rats indicated that postnursing maps were composed of either contiguous (two-thirds of the maps) or fragmented (one-third of the maps) representation zones interspersed with noncutaneous patches (Fig. 5). No such fragmented representations have been recorded in virgin or primiparous non-nursing rats. The temporal decoupling in the time course of nursing-induced changes in RF sizes and areal extent of representation is well illustrated in Figure 6, showing three maps that could be obtained, for the first time, in the same rat.

\section{Western blot analysis}

We attempted to determine whether the temporal decoupling between RF contraction and map expansion over the nursing period was accompanied by temporally separable changes in excitatory and inhibitory neurotransmission. First, we tracked changes in the expression of GAD 65/67, two genetically independent isoforms of the synthesizing enzyme for GABA (Erlander et al., 1991; Bu et al., 1992) $\alpha$-CaMKII and NMDAR subunit NR2A, by comparing matched postpartum nursing and non-nursing rats at two particular stages of reorganization: (1) when RF sizes were found to decrease while the cortical map areal extent remained unchanged ( 6 d postpartum) and (2) when RF sizes returned to prenursing values while cortical maps still exhibited an expansion (21 d postpartum). Second, immunoblotting data were obtained in nursing rats at all other postpartum times of map reorganization examined in the electrophysiological investigation.

\section{GAD 65 and 67 are upregulated as RF sizes are decreased and map area is unchanged}

For the GAD 65 and 67 proteins examined at 6 and $21 \mathrm{~d}$ postpartum in nursing and non-nursing rats, ANOVA yielded significant effects of nursing $\left(F_{(1,20)}=15.24, p<\right.$ 0.002 ; and $F_{(1,20)}=17.55, p<0.002$, respectively) and postpartum period $\left(F_{(1,20)}\right.$ $=7.85, p<0.04$; and $F_{(1,20)}=6.60, p<$ 0.05 , respectively). After $6 \mathrm{~d}$ of nursing, levels of GAD 65 and 67 proteins were significantly greater $(1.19 \pm 0.27$ and $1.47 \pm$ 0.40 , respectively) than those recorded in matched non-nursing rats (GAD 65, $0.46 \pm 0.14 ; \mathrm{GAD} 67,0.83 \pm 0.14 ; p<$ 0.003 and $p<0.007$, respectively, Newman-Keuls test) (Fig. 7B). Conversely, after $21 \mathrm{~d}$ of nursing, amounts of GAD 65 and 67 were substantially decreased $(p<$ 0.01 and $p<0.03$, respectively, NewmanKeuls test), so that no significant difference was found between nursing (GAD 65, $0.76 \pm 0.31 ;$ GAD 67, $1.11 \pm 0.11)$ and non-nursing (GAD 65, $0.42 \pm 0.15, p=$ 0.43 ; GAD $67,0.85 \pm 0.25, p=0.16$ ) rats. Thus, levels of GAD 65 and 67 proteins were found to be upregulated at a time point in nursing when RF sizes were smaller and the ventrum representation not yet in expansion.

The time course of changes in GAD 65 and 67 expression was evaluated using complementary data obtained in virgins and nursing rats ( $12 \mathrm{~d}$ postpartum, and $15 \mathrm{~d}$ after $21 \mathrm{~d}$ of nursing). ANOVA reveals that the levels of GAD 65 and 67 were significantly modulated over the time course of nursing $\left(\mathrm{GAD} 65, F_{(4,25)}=12.57, p<0.0001 ; \mathrm{GAD} 67, F_{(4,25)}=8.41, p<\right.$ $0.0002)$. These proteins exhibited a peak expression at $6 \mathrm{~d}$ of nursing and subsequently decreased as nursing time declined, so that values obtained at $21 \mathrm{~d}$ postpartum were not different from those in virgins (GAD 65, $p=0.07$; GAD 67, $p=0.90$ ) or $15 \mathrm{~d}$ after nursing (GAD 65, $p=0.09$; GAD 67, $p=0.29$ ) (Fig. $7 C$ ).

NMDAR NR2A subunit and $\boldsymbol{\alpha}$-CaMKII are overexpressed as cortical map is expanded and RF size is unchanged

For the NMDAR NR2A protein examined at 6 and $21 \mathrm{~d}$ postpartum in nursing and non-nursing rats, ANOVA yielded significant effects of nursing $\left(F_{(1,20)}=30.50 ; p<0.0002\right)$ and postpartum period $\left(F_{(1,20)}=10.86 ; p<0.002\right)$. At day 6 postpartum, NR2A subunit expression did not differ between nursing $(1.27 \pm 0.22)$ and non-nursing rats $(1.14 \pm 0.18 ; p=0.21$, Newman-Keuls test). The protein was upregulated in females that lactated for $21 \mathrm{~d}(1.79 \pm 0.37)$ compared with the matched non-nursing rats $(1.11 \pm 0.22 ;(p<0.0002$, Newman-Keuls test $)$ and to the rats which lactated for $6 \mathrm{~d}(1.27 \pm 0.22 ; p<0.0001$, Newman-Keuls test) (Fig. $8 A, B$ ). For the $\alpha$-CaMKII protein, ANOVA yielded significant effects of nursing $\left(F_{(1,20)}=32.36 ; p<0.0003\right)$ and 
11 days post-partum

A

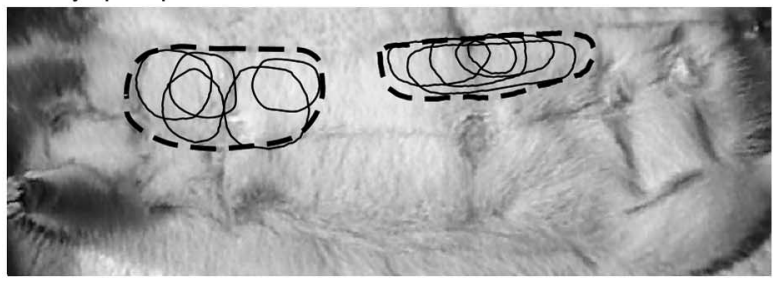

21 days post-partum

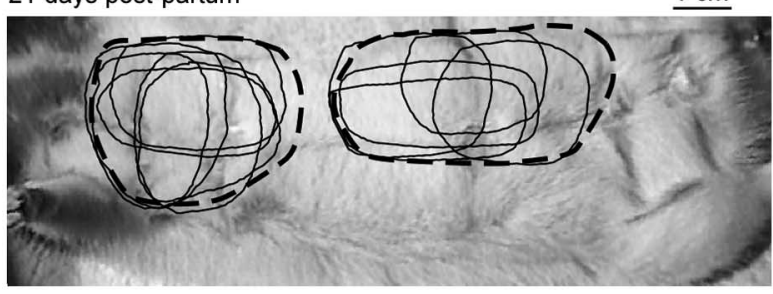

C

RF size (\% of ventrum surface)

RF size (\% of multi-unit RF)

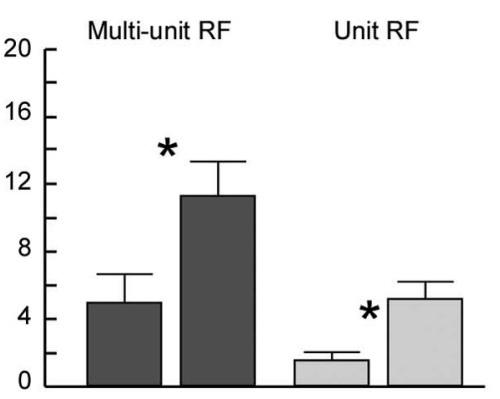

11-12 d 21-22 d 11-12 d 21-22 d

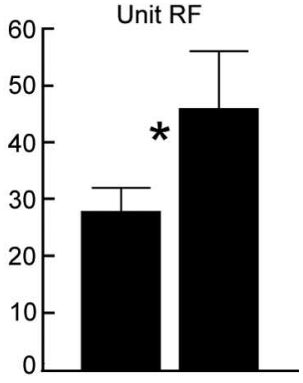

$11-12$ d $21-22$ d
Figure 4. Modifications of single-unit RFs between two time points of nursing. $A, B$, Examples of multiunit (broken outlines) and single-unit (thin outlines) RFs recorded within layer IV at 11 and $21 \mathrm{~d}$ postpartum in the same nursing rat. The single-unit RFs of all neurons sampled in individual microelectrode penetrations displayed some variations in size and shape but overlapped to some extent. They appeared, in almost all instances, to be completely contained within the multiunit RF recorded in the corresponding penetration but displayed some variation in the locations of their centers. C, RFs normalized relative to the ventrum skin surface. $\boldsymbol{D}$, Single-unit RFs normalized relative to the area of their corresponding multiunit RF. ${ }^{*}$ Statistically significant differences (Wilcoxon's test, $p<0.002$ ).

postpartum period $\left(F_{(1,20)}=10.35 ; p<0.005\right)$. At $6 \mathrm{~d}$ postpartum, levels of enzyme were not statistically different in nursing $(1.50 \pm 0.27)$ and non-nursing $(1.24 \pm 0.26 ; p=0.13$, NewmanKeuls test) rats. In contrast, the protein was overexpressed in females that had nursed their pups for $21 \mathrm{~d}(1.99 \pm 0.33)$ compared with the matched non-nursing rats $(1.27 \pm 0.25 ; p<$ 0.0002, Newman-Keuls test) and with the females that had lactated for $6 \mathrm{~d}(1.50 \pm 0.27 ; p<0.0008$, Newman-Keuls test) (Fig. $8 A, B)$. Consequently, concentrations of NR2A and $\alpha$-CaMKII were found to be increased at a time point when the ventrum map was expanding, whereas RFs were similar in size to non-nursing values.

The time courses of changes in expression of NMDAR NR2A subunit and $\alpha$-CaMKII proteins were examined using additional data collected in virgin and nursing rats ( $12 \mathrm{~d}$ postpartum, and $15 \mathrm{~d}$ after $21 \mathrm{~d}$ of nursing). NMDAR NR2A subunit expression was found to be greater at $21 \mathrm{~d}$ of nursing $\left(F_{(4,25)}=11.83 ; p<\right.$ $0.0002)$, suggesting that an increase occurred between 12 and $21 \mathrm{~d}$
A

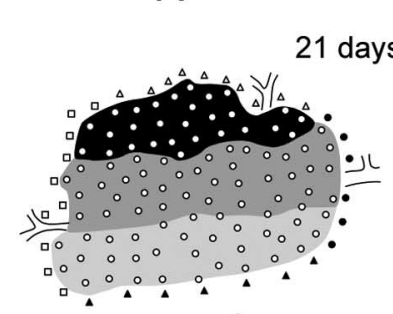

$1.00 \mathrm{~mm}^{2}$

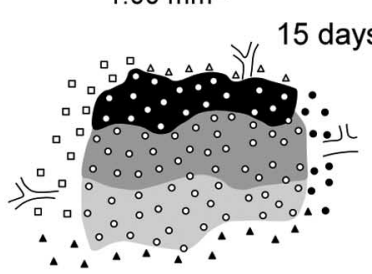

$0.66 \mathrm{~mm}^{2}$ $1 \mathrm{~mm}$

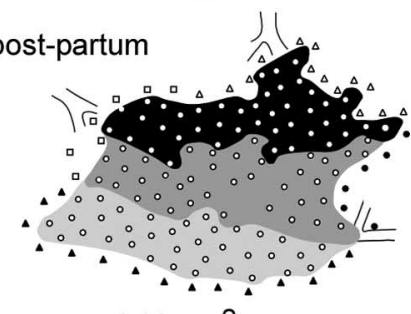

$0.99 \mathrm{~mm}^{2}$
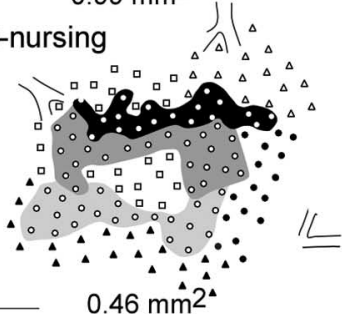

21 days post-partum

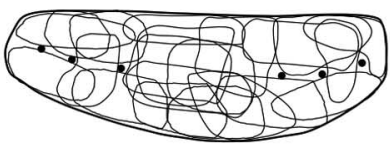

$12.50 \pm 2.92 \%$

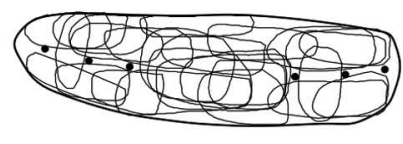

$10.30 \pm 3.33 \%$
15 days post-nursing

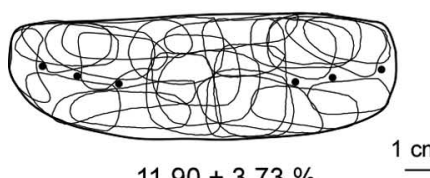

$11.90 \pm 3.73 \%$

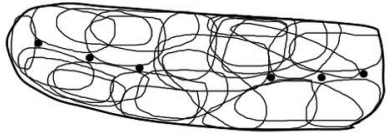

$13.60 \pm 2.45 \%$
Figure 5. Reversibility of the nursing-induced expansion of ventrum representational map. Top, Paired cortical maps obtained in two nursing rats at days 21 postpartum and 15 after nursing. The ventrum representations were restricted to smaller cortical territories within $15 \mathrm{~d}$ after the end of nursing. The territories of the postnursing maps were either contiguous as in pre-nursing maps $(\boldsymbol{A})$ or appeared to be composed of fragmented representation zones interspersed with noncutaneous patches $(\boldsymbol{B})$. Bottom, RFs defined on the ventrum skin at the recording sites shown in the corresponding maps. Note that the RFs recorded in these paired cortical areas displayed similar sizes (same conventions as in Fig. 3).

(Fig. $8 B$ ). ANOVA indicates that the levels of $\alpha$-CaMKII were significantly modulated over the time course of nursing $\left(F_{(4,25)}=\right.$ 10.25 ; $p<0.0005)$. $\alpha$-CaMKII expression was greater after $12 \mathrm{~d}$ of nursing, remained overexpressed at $21 \mathrm{~d}$ of nursing, and returned to baseline $15 \mathrm{~d}$ after nursing (Fig. 8C).

\section{Discussion}

We used nursing as a naturalistic source of rapidly evolving and reversible changes in cutaneous inputs to search for molecular mechanisms involved in the development, maintenance, and reversibility of experience-dependent cortical reorganization of somatosensory maps.

\section{Temporal decoupling between alterations of RF size and map} areal extent

We show that cutaneous RF sharpening occurred rapidly in a naturalistic context (Polley et al., 2004). This change occurred after $6 \mathrm{~d}$ of nursing and several days before cortical map expansion was obvious. Few of the studies that investigated experiencedependent changes addressed the question of how these changes developed over time but assessed alterations once cortical reor- 

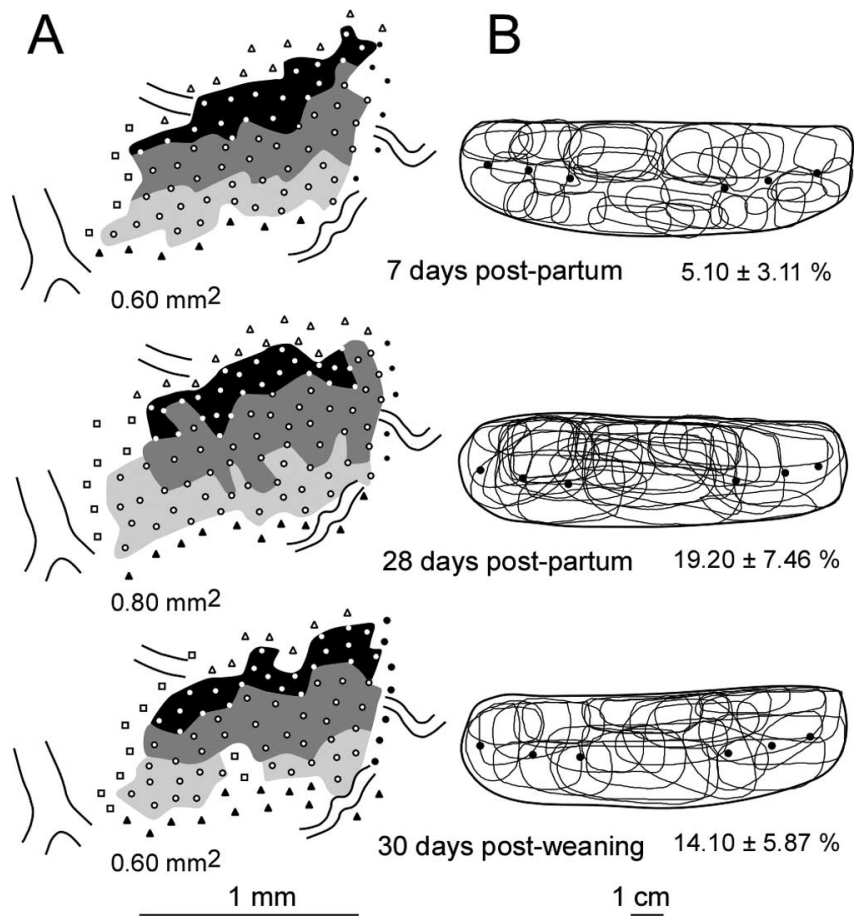

Figure 6. Topographic organization of the ventrum map evolving with maternal behavior. Three ventrum maps could be derived from the same nursing rat at days 7 and 28 postpartum and $30 \mathrm{~d}$ after weaning. Nursing-dependent expansion/contraction of the ventrum representation $(\boldsymbol{A})$ and changes in neuron RF sizes $(\boldsymbol{B})$ did not evolve in parallel. The map expansion was not observed at the end of the first week postpartum, whereas RFs were restricted to smaller skin regions. Such a representational expansion was observed despite the cessation of stimulation induced by nursing at the time of weaning, whereas RFs were found to exhibit normal sizes. In this rat, the map contraction was assessed 1 month after weaning.

ganization had reached a relatively stable state (but see Dupont et al., 2001; Blake et al., 2005). Therefore, the early decoupling described herein may have been overlooked in most studies. Map expansion occurred several days after the onset of RF contraction. In addition, we found that RFs regained prenursing sizes at the end of week 3 postpartum, as nursing time declined to $\sim 30 \%$, whereas the cortical map displayed a maximal areal extent. Moreover, our data suggests that map expansion was reversed over 2 weeks after nursing. This finding seems at variance with those reported by Dupont et al. (2001). After hindlimb suspension in rats, the cortical hindpaw representation was reduced, whereas cutaneous RFs were enlarged. These changes were reversed within a few hours of free limb use. One can assume that the cortical representation was "passively" reshaped after a sudden reduction in all somatosensory inputs from the hindpaw, similar to a deafferentation effect. Consistently, the restoration of normal pattern of input allowed all cutaneous afferents to drive their original neuronal targets simultaneously. On the contrary, ventrum skin representations were gradually remodeled by nursinginduced ongoing alterations in the pattern of cutaneous inputs through a competitive process (Buonomano and Merzenich, 1998).

Our findings suggest that cortical neuron RFs were reshaped on a timescale closely dependent on behaviorally driven changes in somatosensory inputs. In contrast, the topographic expansion of the cortical map may depend on a protracted process that changed relatively slowly to/from a stable state in a rapidly evolving nursing behavior. These results raise the intriguing possibility
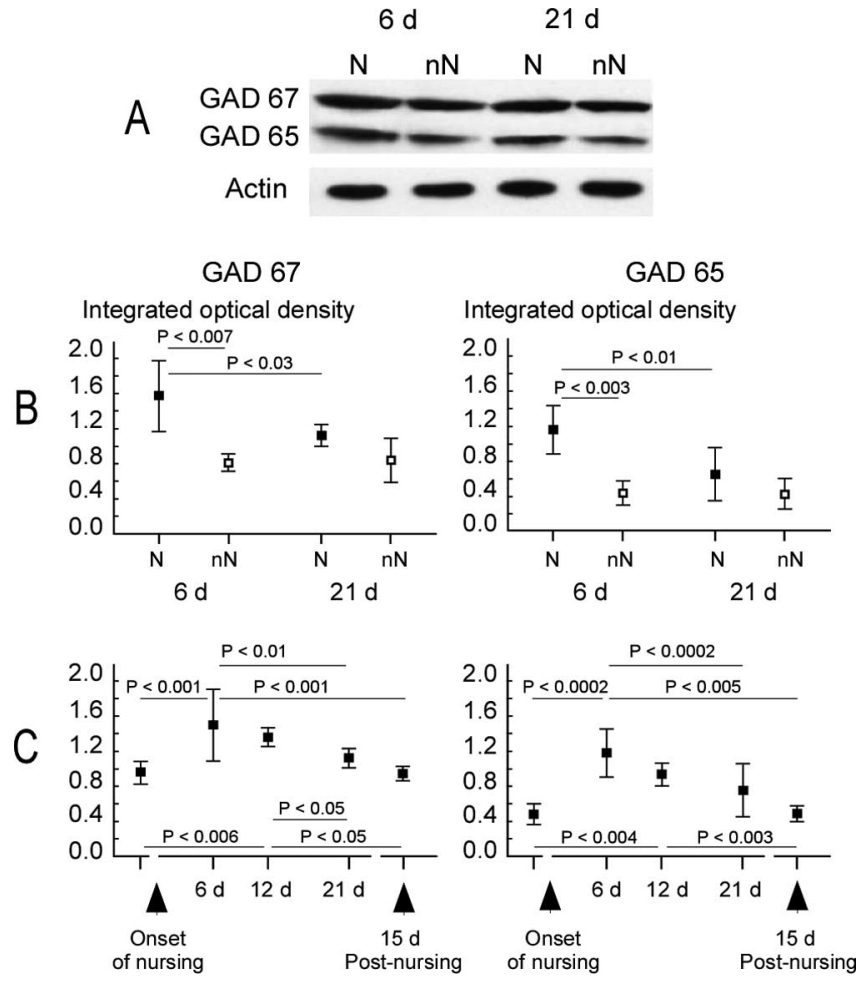

Figure 7. Modulation of GAD protein expression in the ventrum area of $\mathrm{SI}$ cortex over the nursing period. $\boldsymbol{A}$, Typical immunoblots for the GAD 67 and 65 proteins in nursing $(\mathrm{N})$ and non-nursing $(\mathrm{nN})$ rats at days 6 and 21 postpartum. Actin controls show that loading was equal for each lane. $B, C$, Mean \pm SD values of ID obtained from quantitative analysis of Western blots in each group of animals. The integrated optical density (ID) values obtained for GAD immunoblots were normalized to the ID of corresponding immunoblots for actin. Significant differences between nursing (filled squares) and non-nursing (open squares) and between 6 and $21 \mathrm{~d}$ postpartum are indicated. No change was recorded in non-nursing mothers $(\boldsymbol{B})$. Both GAD 67 and 65 proteins were upregulated after 6 and 12 nursing days but not after $21 \mathrm{~d}$. In lactating rats, levels of GAD 67 and 65 proteins gradually decreased to control levels from $6 \mathrm{~d}$ postpartum, as daily nursing time decreased (C). Statistically significant differences are indicated (NewmanKeuls post hoc comparisons).

that RF size and cortical area changes may be sustained by distinct plasticity mechanisms operating on different timescales.

\section{Nursing-dependent regulation of GABAergic inhibition and cutaneous RF sharpening}

We recorded increased levels of GAD 65 and 67 proteins after 6 and $12 \mathrm{~d}$ of nursing, i.e., within a nursing period in which pups spent $\sim 80$ and $55 \%$ of their time suckling accompanied with intensive stimulation of the nipple-bearing and neighboring skin. As daily nursing time decreased to $\sim 30 \%$, the amounts of both GAD proteins were found to drop to prenursing levels. These findings corroborate studies showing that GABAergic inhibition is also regulated in an experience-dependent manner. For example, whisker trimming or nerve transection were found to reduce GAD immunostaining or $\mathrm{GABA}_{\mathrm{A}}$ receptor binding within layer IV of the deprived cortical zone (Akhtar and Land, 1991; Land et al., 1995; Wellman et al., 2002). Prolonged stimulation of a set of whiskers increases GAD immunoreactivity in layer IV of the corresponding region of the barrel cortex (Welker et al., 1989b). Furthermore, a greater density of GABA-immunoreactive neurons (Siucinska et al., 1999), upregulation of GAD 67 protein (Gierdalski et al., 2001), and increased expression of $\mathrm{GABA}_{\mathrm{A}}$ receptor mRNA (Lech et al., 2001) were found in layer IV of the 

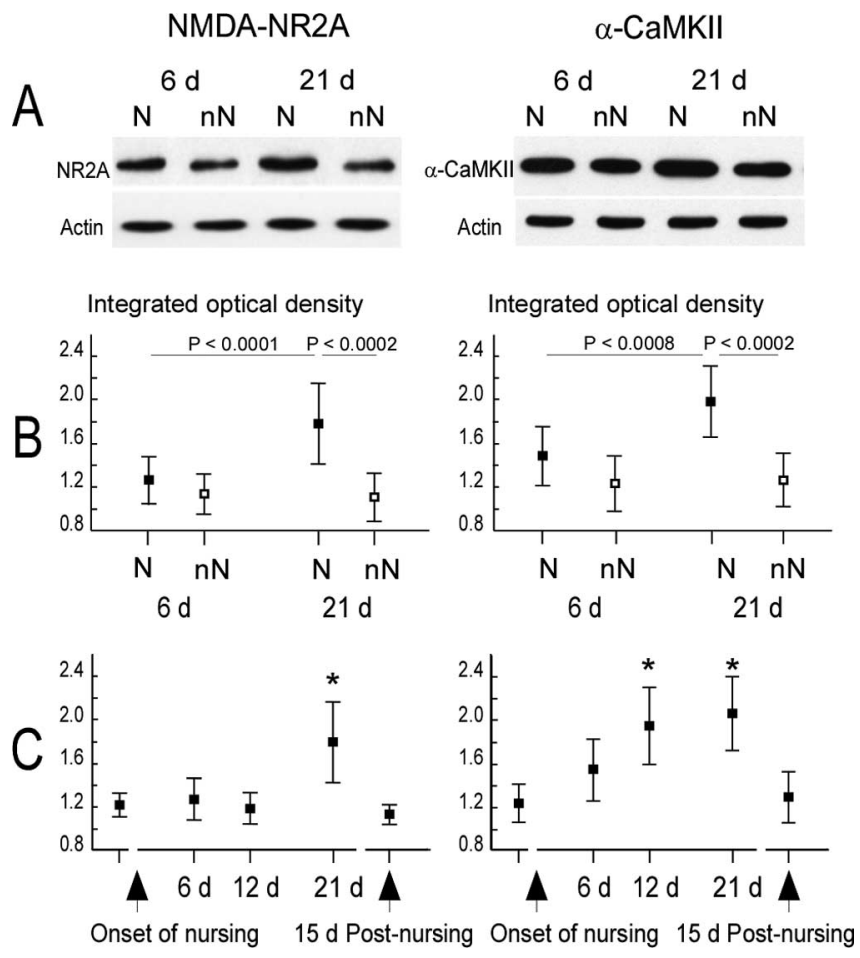

Figure 8. Modulation of the expression of NMDA-NR2A subunit and $\alpha$-CaMKII proteins in the ventrum area of $S I$ cortex over the nursing period. $A$, Representative immunoblots for the NMDA-NR2A subunit and $\alpha$-CaMKII proteins in nursing $(\mathrm{N})$ and non-nursing $(\mathrm{nN})$ rats at days 6 and 21 postpartum. Actin controls show that loading was equal for each lane. $B, C$, Mean \pm SD values of integrated optical density computed from quantitative analysis of Western blots in each group of animals, after normalization to actin. Significant differences between nursing (filled squares) and non-nursing (open squares) and between 6 and $21 \mathrm{~d}$ postpartum are indicated $(\boldsymbol{B})$. NR2A protein expression was only increased at $21 \mathrm{~d}$ of nursing (i.e., 1 week before weaning), whereas $\alpha$-CaMKII protein expression gradually increased after $6 \mathrm{~d}$ of nursing, peaked at 12 and $21 \mathrm{~d}$, and returned to the baseline $15 \mathrm{~d}$ after the end of nursing (C). ${ }^{*}$ Significant differences versus all other groups (maximum $p$ values: NR2A, $p<0.0002 ; \alpha$-CaMKII, $p<$ 0.02; Newman-Keuls post hoc comparisons).

barrel cortex after a short period of classical conditioning involving a row of vibrissae.

Our data reveals that GAD 65 and 67 were upregulated at a time when RFs were smaller and were downregulated to prenursing levels as RF sizes returned to normal. These findings are in agreement with the available evidence from other studies suggesting that the shrinkage of RFs may be ascribed to increased levels of GAD, very likely through suppression of suprathreshold excitatory inputs. Accordingly, RF re-enlargement could be attributed to normalization of GABA synthesis, leading to unmasking of previously effective excitatory connections. This view is consistent with studies showing an expansion of cutaneous RFs in the SI cortex when GABA-mediated local inhibition was antagonized (Dykes et al., 1984; Alloway et al., 1989; Tremere et al., 2001b; Chowdhury and Rasmusson, 2002; Li et al., 2002). Moreover, deprivation-induced whisker map plasticity was found to depend on $\mathrm{GABA}_{\mathrm{A}}$ inhibitory sharpening of SI neuron RFs around the spared whisker (Foeller et al., 2005).

Expression of $\alpha$-CaMKII kinase was increased at two nursing time points in which RF sizes (1) were smaller and (2) returned to normal dimensions. This result is not compatible with an involvement of $\alpha$-CaMKII in RF reshaping. Interestingly, the sizes of barrel cortex neuron RFs did not differ between wild-type and $\alpha$-CaMKII knock-out mice (Glazewski et al., 2000). Both $\alpha$-CaMKII and NMDAR NR2A proteins were found in greater amounts after $21 \mathrm{~d}$ of nursing, as RFs were enlarged to normal sizes, but were downregulated at $15 \mathrm{~d}$ after nursing, whereas RFs were still normal sized. Therefore, our data suggest that, unlike GABA inhibition, NMDA-mediated glutamatergic excitation was not critically involved in RF size reshaping. This hypothesis is in keeping with results showing that L-glutamate injected within the SI cortex increased cortical excitability but did not change RF sizes (Tremere et al., 2001a).

\section{Involvement of glutamatergic excitation in somatosensory map expansion}

Expansion of topographic representations implies large-scale orderly shifts of RFs on nearby or distant skin territories. In addition, neurons at the boundaries of the map that previously displayed noncutaneous responses exhibit emerging cutaneous RFs. The question arises as to whether a reduction in GABA inhibition related to a decreasing nursing time contributed to the expansion of the ventrum representation, through unmasking weak connections. We reported a GAD enhancement within an intermediate period in which small RFs coexisted with map expansion. Thus, the hypothesis that decreased GABAergic inhibition contributed to the induction of map enlargement is not plausible. Furthermore, it seems difficult to conciliate the RF shrinkage, tightly dependent on an increased inhibition, with a representational expansion hypothetically sustained by a decreased inhibition. We show that, toward the end of the nursing period, when cortical maps displayed a maximum expansion, the levels of GAD proteins were not different from control, suggesting that changes in GABA synthesis did not account for protraction of the representational expansion.

Levels of $\alpha$-CaMKII expression increased in parallel with map expansion and were maintained at higher levels as long as the map remained expanded. There is growing evidence that $\alpha$-CaMKII kinase plays a major role in the enhancement of excitatory synaptic transmission underlying sensory plasticity in the adult neocortex. Interestingly, in a single-whisker paradigm, expansion of the spared vibrissa representation is impaired in $\alpha$-CaMKII knock-out mice (Glazewski et al., 1996), as it is in mice carrying a point mutation of the $\alpha$-CaMKII gene at its phosphorylation site. Because LTP cannot be induced in these mutant mice, the expansion of SI cortical representation has been proposed to require LTP-like mechanisms (Hardingham et al., 2003). Our data show a long-term, but not short-term, experience-dependent regulation of $\alpha$-CaMKII genetic expression in SI (Skibinska et al., 2001).

NMDAR NR2A subunit level was increased at the end of nursing. High levels of NMDAR activation are known to produce synaptic potentiation (Cummings et al., 1996), which could play a crucial role in experience-dependent map expansion. We hypothesize that $\alpha$-CaMKII activation induces an LTP-like process that involves NMDAR NR2A subunit, a direct or indirect target of the kinase in the postsynaptic density (Gardoni et al., 1998, 1999, 2003). Blockade of NMDAR in the adult SI cortex disrupts the expansion of intact representational zones within the deprived area but does not affect an already expanded map (Kano and Iino, 1991; Jablonska et al., 1995; Garraghty and Muja, 1996). Our study shows that the NMDAR NR2A subunit is mainly involved in the protraction of map expansion. Accordingly, the expansion of the ventrum map would be maintained through enduring imbalance of competitive excitatory inputs. This study is the first to relate to NMDAR and maintenance of SI map expansion in a use-dependent context. Indeed, our data complete previous investigations showing that short-term expansion of 
whisker representation in adult rat barrel cortex requires NMDAR activation (Rema et al., 1998; Jablonska et al., 1999). Functionally, NR2A subunit has been described as an activitydependent molecule regulated by sensory experience and playing a crucial role in the expression of cortical LTP (Massey et al., 2004), which seems consistent with the nursing-induced upregulation of NR2A. Along the same line, tactile training in a conditioning paradigm increases NR2A expression, as shown in both mRNA and protein levels within layer IV of the barrel cortex (Skibinska et al., 2005).

The present study brings evidence that experience-dependent cortical map remodeling involves time-decoupled and reversible changes in RF size and location/submodality. Furthermore, our data suggests that nursing-induced modulation of GABAergic inhibition plays a critical role in sharpening cortical neuron RFs, whereas increases in the NMDA-dependent synaptic efficacy would mainly contribute to representational expansion of behaviorally salient inputs in SI.

\section{References}

Akhtar ND, Land PW (1991) Activity-dependent regulation of glutamic acid decarboxylase in the rat barrel cortex: effects of neonatal versus adult sensory deprivation. J Comp Neurol 307:200-213.

Alloway KD, Rosenthal P, Burton H (1989) Quantitative measurements of receptive field changes during antagonism of GABAergic transmission in primary somatosensory cortex of cats. Exp Brain Res 78:514-532.

Barria A, Malinow R (2002) Subunit-specific NMDA receptor trafficking to synapses. Neuron 35:345-353.

Blake DT, Strata F, Kempter R, Merzenich MM (2005) Experiencedependent plasticity in S1 caused by noncoincident inputs. J Neurophysiol 94:2239-2250.

Bradford MM (1976) A rapid and sensitive method for the quantitation of microgram quantities of protein utilizing the principle of protein-dye binding. Anal Biochem 72:248-254.

Bu DF, Erlander MG, Hitz BC, Tillakaratne NJ, Kaufman DL, WagnerMcPherson CB, Evans GA, Tobin AJ (1992) Two human glutamate decarboxylases, $65-\mathrm{kDa}$ GAD and 67-kDa GAD, are each encoded by a single gene. Proc Natl Acad Sci USA 89:2115-2119.

Buonomano DV, Merzenich MM (1998) Cortical plasticity: from synapses to maps. Annu Rev Neurosci 21:149-186.

Calford MB (2002) Dynamic representational plasticity in sensory cortex. Neuroscience 111:709-738.

Chapin JK, Lin CS (1984) Mapping the body representation in the SI cortex of anesthetized and awake rats. J Comp Neurol 229:199-213.

Chowdhury SA, Rasmusson DD (2002) Comparison of receptive field expansion produced by $\mathrm{GABA}(\mathrm{B})$ and $\mathrm{GABA}(\mathrm{A})$ receptor antagonists in raccoon primary somatosensory cortex. Exp Brain Res 144:114-121.

Coq JO, Xerri C (1998) Environmental enrichment alters organizational features of the forepaw representation in the primary somatosensory cortex of adult rats. Exp Brain Res 121:191-204.

Cummings JA, Mulkey RM, Nicoll RA, Malenka RC (1996) $\mathrm{Ca}^{2+}$ signaling requirements for long-term depression in the hippocampus. Neuron 16:825-833.

Dupont E, Canu MH, Langlet C, Falempin M (2001) Time course of recovery of the somatosensory map following hindpaw sensory deprivation in the rat. Neurosci Lett 309:121-124.

Dykes RW, Landry P, Metherate R, Hicks TP (1984) Functional role of GABA in cat primary somatosensory cortex: shaping receptive fields of cortical neurons. J Neurophysiol 52:1066-1093.

Erlander MG, Tillakaratne NJ, Feldblum S, Patel N, Tobin AJ (1991) Two genes encode distinct glutamate decarboxylases. Neuron 7:91-100.

Foeller E, Celikel T, Feldman DE (2005) Inhibitory sharpening of receptive fields contributes to whisker map plasticity in rat somatosensory cortex. J Neurophysiol 94:4387-4400.

Gardoni F, Caputi A, Cimino M, Pastorino L, Cattabeni F, Di Luca M (1998) Calcium/calmodulin-dependent protein kinase II is associated with NR2A/B subunits of NMDA receptor in postsynaptic densities. J Neurochem 71:1733-1741.

Gardoni F, Schrama LH, van Dalen JJ, Gispen WH, Cattabeni F, Di Luca M (1999) AlphaCaMKII binding to the C-terminal tail of NMDA receptor subunit NR2A and its modulation by autophosphorylation. FEBS Lett 456:394-398.

Gardoni F, Mauceri D, Fiorentini C, Bellone C, Missale C, Cattabeni F, Di Luca M (2003) CaMKII-dependent phosphorylation regulates SAP97/ NR2A interaction. J Biol Chem 278:44745-44752.

Garraghty PE, Muja N (1996) NMDA receptors and plasticity in adult primate somatosensory cortex. J Comp Neurol 367:319-326.

Gierdalski M, Jablonska B, Siucinska E, Lech M, Skibinska A, Kossut M (2001) Rapid regulation of GAD67 mRNA and protein level in cortical neurons after sensory learning. Cereb Cortex 11:806-815.

Glazewski S, Chen CM, Silva A, Fox K (1996) Requirement for alphaCaMKII in experience-dependent plasticity of the barrel cortex. Science 272:421-423.

Glazewski S, Giese KP, Silva A, Fox K (2000) The role of alpha-CaMKII autophosphorylation in neocortical experience-dependent plasticity. Nat Neurosci 3:911-918.

Grota LJ, Ader R (1969) Effects of litter size on emotionality, adrenocortical reactivity, and susceptibility to gastric erosions in the rat. Psychol Rep 24:547-549.

Grota LJ, Ader R (1974) Behavior of lactating rats in a dual-chambered maternity cage. Horm Behav 5:275-282.

Hardingham N, Glazewski S, Pakhotin P, Mizuno K, Chapman PF, Giese KP, Fox K (2003) Neocortical long-term potentiation and experiencedependent synaptic plasticity require $\alpha$-calcium/calmodulin-dependent protein kinase II autophosphorylation. J Neurosci 23:4428-4436.

He HY, Rasmusson DD, Quinlan EM (2004) Progressive elevations in AMPA and GABAA receptor levels in deafferented somatosensory cortex. J Neurochem 90:1186-1193.

Jablonska B, Gierdalski M, Siucinska E, Skangiel-Kramska J, Kossut M (1995) Partial blocking of NMDA receptors restricts plastic changes in adult mouse barrel cortex. Behav Brain Res 66:207-216.

Jablonska B, Kossut M, Skangiel-Kramska J (1996) Transient increase of AMPA and NMDA receptor binding in the barrel cortex of mice after tactile stimulation. Neurobiol Learn Mem 66:36-43.

Jablonska B, Gierdalski M, Kossut M, Skangiel-Kramska J (1999) Partial blocking of NMDA receptors reduces plastic changes induced by shortlasting classical conditioning in the SI barrel cortex of adult mice. Cereb Cortex 9:222-231.

Jenkins WM, Merzenich MM, Ochs MT, Allard T, Guic-Robles E (1990) Functional reorganization of primary somatosensory cortex in adult owl monkeys after behaviorally controlled tactile stimulation. J Neurophysiol 63:82-104.

Kano M, Iino K (1991) Functional reorganization of adult cat somatosensory cortex is dependent on NMDA receptors. NeuroReport 2:77-80.

Kind PC, Neumann PE (2001) Plasticity: downstream of glutamate. Trends Neurosci 24:553-555.

Knott GW, Quairiaux C, Genoud C, Welker E (2002) Formation of dendritic spines with GABAergic synapses induced by whisker stimulation in adult mice. Neuron 34:265-273.

Land PW, de Blas AL, Reddy N (1995) Immunocytochemical localization of GABAA receptors in rat somatosensory cortex and effects of tactile deprivation. Somatosens Mot Res 12:127-141.

Lech M, Skibinska A, Kossut M (2001) Delayed upregulation of GABA(A) alpha1 receptor subunit mRNA in somatosensory cortex of mice following learning-dependent plasticity of cortical representations. Brain Res Mol Brain Res 96:82-86.

Li CX, Callaway JC, Waters RS (2002) Removal of GABAergic inhibition alters subthreshold input in neurons in forepaw barrel subfield (FBS) in rat first somatosensory cortex (SI) after digit stimulation. Exp Brain Res 145:411-428.

Lisman J, Schulman H, Cline H (2002) The molecular basis of CaMKII function in synaptic and behavioural memory. Nat Rev Neurosci 3:175-190

Liu L, Wong TP, Pozza MF, Lingenhoehl K, Wang Y, Sheng M, Auberson YP, Wang YT (2004) Role of NMDA receptor subtypes in governing the direction of hippocampal synaptic plasticity. Science 304:1021-1024.

Lledo PM, Hjelmstad GO, Mukherji S, Soderling TR, Malenka RC, Nicoll RA (1995) Calcium/calmodulin-dependent kinase II and long-term potentiation enhance synaptic transmission by the same mechanism. Proc Natl Acad Sci USA 92:11175-11179.

Malenka RC, Nicoll RA (1999) Long-term potentiation: a decade of progress? Science 285:1870-1874. 
Massey PV, Johnson BE, Moult PR, Auberson YP, Brown MW, Molnar E, Collingridge GL, Bashir ZI (2004) Differential roles of NR2A and NR2B-containing NMDA receptors in cortical long-term potentiation and long-term depression. J Neurosci 24:7821-7828.

Peterson BE, Merzenich MM (1995) MAP: a Macintosh program for generating categorical maps applied to cortical mapping. J Neurosci Methods 57:133-144.

Polley DB, Kvasnak E, Frostig RD (2004) Naturalistic experience transforms sensory maps in the adult cortex of caged animals. Nature 429:67-71.

Quinlan EM, Philpot BD, Huganir RL, Bear MF (1999) Rapid experiencedependent expression of synaptic NMDA receptors in visual cortex in vivo. Nat Neurosci 2:352-357.

Recanzone GH, Merzenich MM, Jenkins WM (1992) Frequency discrimination training engaging a restricted skin surface results in an emergence of a cutaneous response zone in cortical area 3a. J Neurophysiol 67:1057-1070.

Rema V, Armstrong-James M, Ebner FF (1998) Experience-dependent plasticity of adult rat $\mathrm{S} 1$ cortex requires local NMDA receptor activation. J Neurosci 18:10196-10206.

Siucinska E, Kossut M, Stewart MG (1999) GABA immunoreactivity in mouse barrel field after aversive and appetitive classical conditioning training involving facial vibrissae. Brain Res 843:62-70.

Skibinska A, Lech M, Kossut M (2001) PSD95 protein level rises in murine somatosensory cortex after sensory training. NeuroReport 12:2907-2910.

Skibinska A, Lech M, Kossut M (2005) Differential regulation of cortical NMDA receptor subunits by sensory learning. Brain Res 1065:26-36.

Taha S, Hanover JL, Silva AJ, Stryker MP (2002) Autophosphorylation of
alphaCaMKII is required for ocular dominance plasticity. Neuron 36:483-491.

Tremere L, Hicks TP, Rasmusson DD (2001a) Expansion of receptive fields in raccoon somatosensory cortex in vivo by $\mathrm{GABA}(\mathrm{A})$ receptor antagonism: implications for cortical reorganization. Exp Brain Res 136:447-455.

Tremere L, Hicks TP, Rasmusson DD (2001b) Role of inhibition in cortical reorganization of the adult raccoon revealed by microiontophoretic blockade of GABA(A) receptors. J Neurophysiol 86:94-103.

Turnbull BG, Rasmusson DD (1991) Chronic effects of total or partial digit denervation on raccoon somatosensory cortex. Somatosens Mot Res 8:201-213.

Waters RS, Li CX, McCandlish CA (1995) Relationship between the organization of the forepaw barrel subfield and the representation of the forepaw in layer IV of rat somatosensory cortex. Exp Brain Res 103:183-197.

Welker E, Soriano E, Van der Loos H (1989a) Plasticity in the barrel cortex of the adult mouse: effects of peripheral deprivation on GADimmunoreactivity. Exp Brain Res 74:441-452.

Welker E, Soriano E, Dorfl J, Van der Loos H (1989b) Plasticity in the barrel cortex of the adult mouse: transient increase of GAD-immunoreactivity following sensory stimulation. Exp Brain Res 78:659-664.

Wellman CL, Arnold LL, Garman EE, Garraghty PE (2002) Acute reductions in GABAA receptor binding in layer IV of adult primate somatosensory cortex after peripheral nerve injury. Brain Res 954:68-72.

Xerri C, Stern JM, Merzenich MM (1994) Alterations of the cortical representation of the rat ventrum induced by nursing behavior. J Neurosci 14:1710-1721. 